Chapter 15

\title{
Colon Cancer: Current Treatments and Preclinical Models for the Discovery and Development of New Therapies
}

\author{
Samuel Constant, Song Huang, \\ Ludovic Wiszniewski and Christophe Mas \\ Additional information is available at the end of the chapter \\ http://dx.doi.org/10.5772/53391
}

\section{Introduction}

More than 10 years after the first sequencing of the human genome and despite major advances in scientific and technological expertise into drug research and development processes (R\&D), the fact remains that we are facing a dearth of new drugs. Indeed, the number of drugs approved by the US Food and Drug Administration (FDA) has roughly fallen to $50 \%$ over the last ten years [1]. Unfortunately for pharmaceutical companies, at present this attrition in drug discovery combined with the expiration of major product patents logically lead to the development of generics. Facing both a major medical need and an obvious economical challenge, there is an urgent need to make significant improvements in the research output.

Analyses of the clinical trials landscape reveal that a large number of promising drug leads fail in late stages, mainly in phase II, with an overall failure rate of $67 \%$ (Fig. 1a). All studies agree on the reasons by pinpointing either insufficient efficacy $(\sim 55 \%)$ or safety issues $(\sim 20 \%)$ as major causes of human trials failure [2,3]. Remarkably, the therapeutic area showing the largest number of failures is oncology, with only $29 \%$ of success rate in Phase II and $34 \%$ in Phase III (Fig.1b). Within oncology indications, the status of colorectal cancer (CRC) is the most dramatic with an overall drug approval of only 3\% (Fig.1c) over the last 10 years! More surprisingly, more than half of the drugs currently approved to treat CRC work through the general inhibition of DNA synthesis and cellular division, instead of targeting molecular processes specifically involved in CRC progression (Table 1). These observations highlight the necessity to both reduce failure rates in the clinic and shorten the time required for developing innovative therapies. 
From this perspective, one of the obvious strategies would be:

1. to directly target the key regulators of CRC cancers

2. to streamline the critical Phase II and Phase III to obtain faster and more reliable responses regarding the drug's efficacy.

This strategy may save years of efforts and millions of dollars, giving that the average usual time for developing a new drug is ten years and with a total cost amount to billions of dollars.

But in contrast, because a new drug has to show a benefit compared to an already approved treatment, the number of patients involved in a pivotal trials is increasing more and more in order to reach significance, and a similar trend is noted for the duration of the trial, that is directly linked to safety. Therefore, regarding the constraints imposed by regulatory authorities nowadays, it seems difficult to save on size and length of clinical trials.

In the mid-1990s, the pharmaceutical community has already attempted to increase R\&D productivity by embarking in a technological shift. That was the time of the inevitable highthroughput screening, which combined with the "all-Omics" supposed to reduce costs and blew up success rates [4]. As we have seen, this approach, maybe too reductionist in the sense that it does not allow getting an idea of the full biological properties (ADME, toxicity,etc...) of a compound at an early stage, has favored the quantity instead of quality and has not kept its promises [1].

Today, efforts have to be made to clearly address the early clinical discovery steps, with the goal to better qualify "leads" to increase the signal-to-noise ratio of drugs entering into clinical trials. This point of view is supported by the important failure rate subsisting in Phases III (Fig1b), suggesting an overestimation of the efficacy of candidate molecules during preclinical tests. One of the important reasons may be the use of irrelevant models or models not predictive enough. Therefore, the development of relevant and predictive models is key to increase the quality of preclinical researches and to increase the success rate of new drugs.

Consequently, the foundations of the drug discovery process have to be reconsidered by giving definitively more emphasis to the quality of preclinical validations and by encouraging the design of new pertinent models, including human 3D (three dimensional) in vitro cell models and tissue explants.

This article is intended to give an overview of the current knowledge about CRC and the different models commonly used to study CRC, in order to identify the most suitable biosystems for optimal development of new CRC therapies. The first part will describe the pathology and its molecular basis, and the various drugs that are currently in clinical use or under development. Then, in the second part we will review and discuss the use of cancer cell line collections, genetically engineered mouse models (GEM), primary human tumors xenografts (PDX) and ex vivo organotypic cultures (EVOC) to identify and validate anticancer colon therapeutics. 


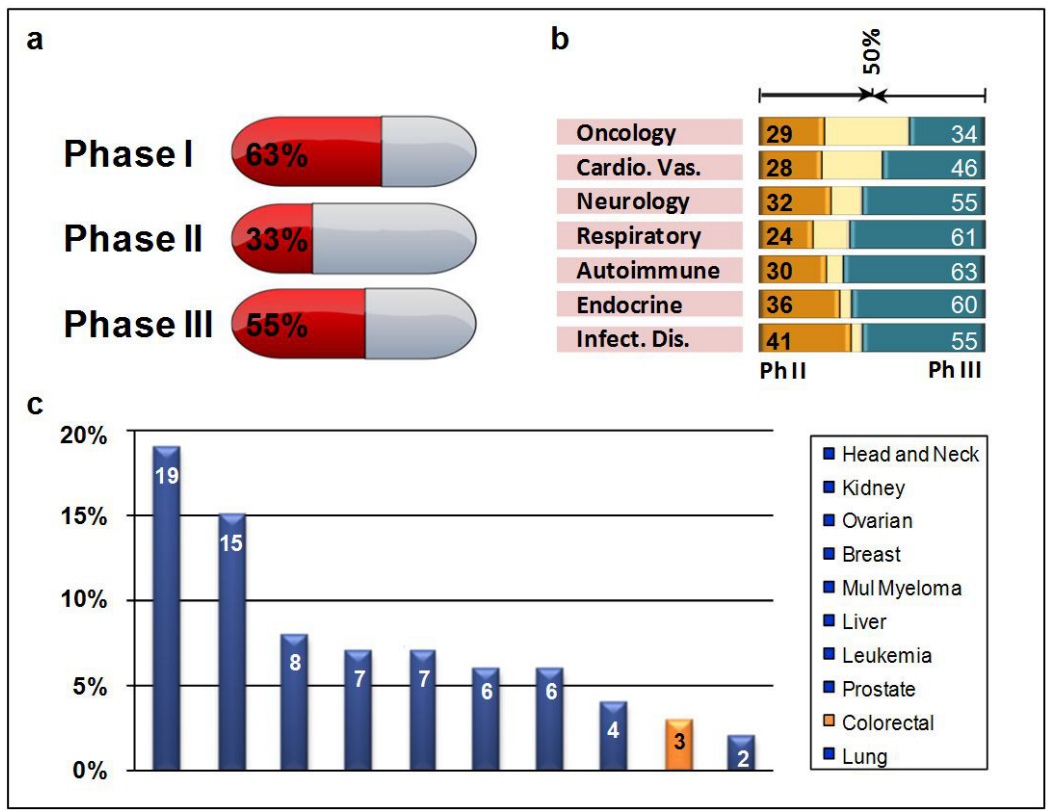

Figure 1. Success rate of drug development. Overall success rate of clinical trials for phases I-III from 2003 to 2010 corresponding to 4275 drugs and 7300 indications (a), success rate for phase II and III divided according to therapeutic areas (b) and overall success rate within specific oncologic areas (c). Source: Hay et al, 13th BIO CEO \& Investor Conference, 2011, New-York.

\section{Colorectal Cancer}

Colorectal cancer is one of the major health concerns in the Western world. CRC is the second most frequently diagnosed cancer in men and women, right after lung cancer. It represents the second leading cause of cancer-related deaths, both in the United States and in Europe, with a significant rate of $9 \%$ and $13 \%$ of total cancer deaths, respectively (Fig.2). The vast majority $(\sim 75 \%)$ of colon cancers are sporadic adenocarcinomas, arising from mutations in the epithelial cells lining the wall of the intestine that is in continuous renewal. CRC often begins as an adenomatous polyp, a benign growth on the interior surface of the organ. Most of polyps remain benign, but over the years some of them become progressively more dysplastic, accumulate mutations and progress to carcinoma and ultimately, to metastasis. 


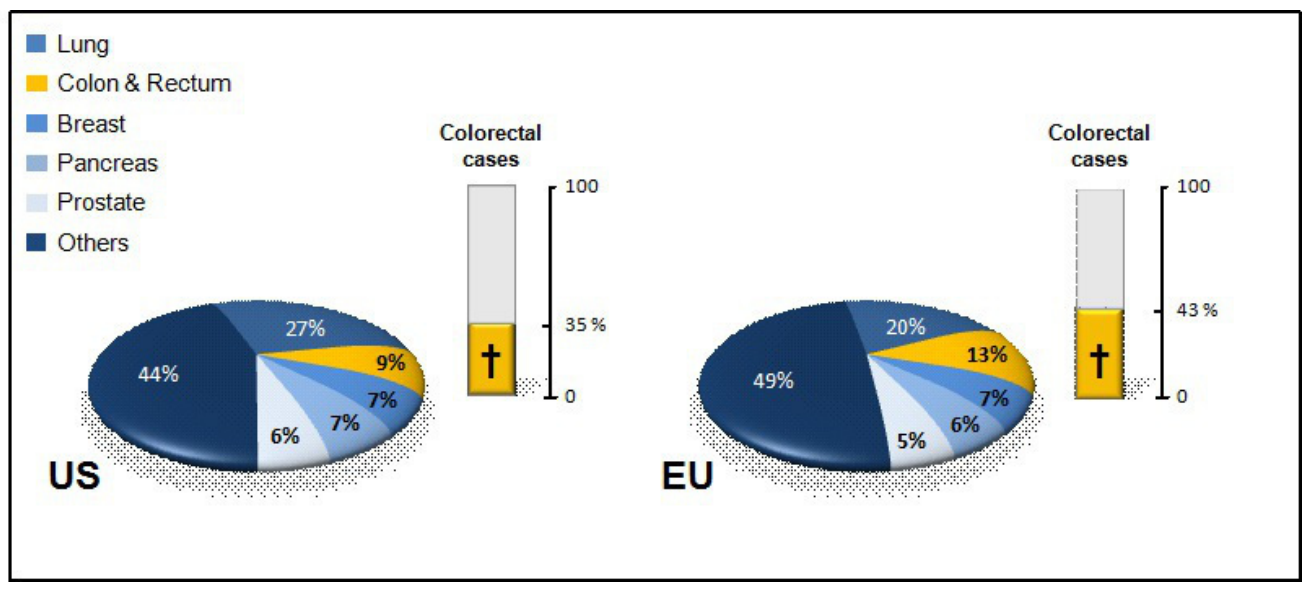

Figure 2. Cancer deaths anticipated in 2011. Estimated leading cancer sites mortality in US and in European Union (EU-27) for the year 2011 expressed as percent of total cancer deaths. Column diagrams highlight the mortality rate within the population specifically affected by colon cancer. Rates are standardized to the World Standard Population. Source: American Cancer Society and Malvezzi et al, Annals of oncology, 2011, 22(4):947-56.

\subsection{Molecular mechanisms}

Loss of APC function is the initial molecular event that leads to adenoma formation. Indeed, germline mutations in the gene APC have been identified as the cause of familial adenomatous polyposis (FAP), an inheritable intestinal cancer syndrome [5], and APC is mutated in more than $80 \%$ of all sporadic cancers [6]. APC belongs to the WNT signaling pathway (Figure 3) where it interacts with other proteins like AXINS and GSK3 $\beta$ to make a complex that down-regulates the cellular levels of $\beta$-CATENIN (see [7] for review). Activating mutations in $\beta$-CATENIN gene have also been observed in more than $10 \%$ of CRC [8]. When activated, $\beta$-CATENIN interacts in the nucleus with the transcriptional complex LEF/TCF to induce the expression of growth promoting genes, like MYC and CYCLIN D1. Additional waves of genetic and epigenetic alterations (KRAS, P53, etc...) will follow this early set of molecular changes to sustain the progression of the transformation process until carcinoma and metastasis stages. 


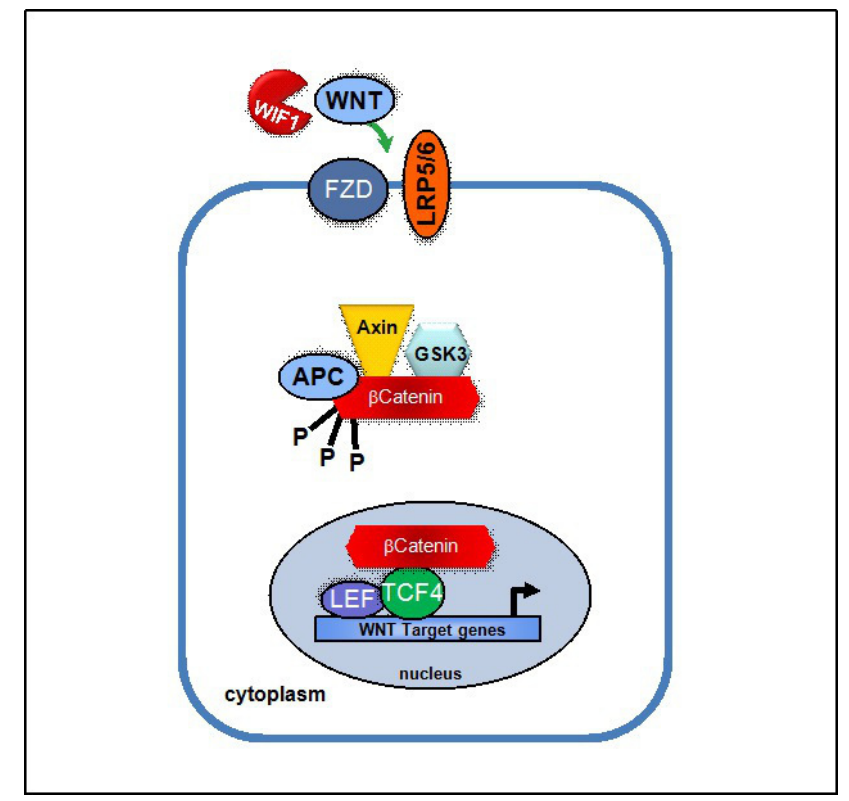

Figure 3. Shematic representation of the WNT signaling pathway. WNT proteins bind to receptors of the Frizzled and LRP families on the cell surface. Through several cytoplasmic components, the signal is transduced to $\beta$-CATENIN, which enters the nucleus and forms a complex with LEF and TCF4 to activate transcription of WNT target genes. Mutations in APC, Axin and $\beta$-CATENIN genes lead to constitutive activation of WNT signaling and ultimately to cancer development.

\subsection{Clinical management}

It is commonly accepted that CRC results from complex interactions between inherited and environmental factors, with a large contribution of dietary and life style factors as suggested by wide geographical risk variations. However, the primary risk factor of CRC is age, as $90 \%$ of the cases are diagnosed over the age of 50 years [9]. Surgical removal remains the most efficient treatment for early stage colorectal cancer, and may be curative for cancers that have not spread. Patients whose cancer is detected at an early, localized stage present a 5-year survival around 90\% [9]. For these reasons, US and European Union have implemented preventive screening programs that have contributed to slightly reduce morbidity and mortality [10].

Unfortunately, as in many other forms of cancer, colon cancer does not display too many symptoms, develops slowly over a period of several years, and only manifests itself when the disease begins to extend. Adjuvant chemotherapy in combination with surgery or radiation is then the usual treatment. However, 5 of the 9 anti-CRC drugs approved by the FDA today are basic cytotoxic chemotherapeutics that attack cancer cells at a very fundamental level (i.e. the cell division machinery) without specific targets, resulting in poor effectiveness and strong side-effects (e.g., oxaliplatin; Table 1). 
Moreover, in more advanced cases, when CRC has spread to distant organs in the form of metastasis and escape any surgical therapy, the 5-year survival dramatically drops to $12 \%$ [9]. These figures underline the urgent need to expand the standard therapy options by turning to more focused therapeutic strategies. In recent years, combination of basic chemotherapies with targeted therapies, in the form of humanized monoclonal antibodies directed against the vascular endothelial growth factor VEGF (Bevacizumab) to prevent the growth of blood vessels to the tumor, or directed against the EGF receptor (Cetuximab, Panitumu$\mathrm{mab}$ ) to block mitogenic factors that promote cancer growth, have been introduced as possible therapeutic protocol and used routinely to treat standard CRCs, as well as metastatic CRCs (Table 1). During the preparation of this manuscript (August 2012), another recombinant protein active against angiogenesis, Aflibercept, has been approved by the FDA for the treatment of metastatic CRC in second-line therapy (Table 1). This new VEGF inhibitor has demonstrated a significant advance over currently available therapy in a Phase III study (improvement in response rate and in overall survival; [11]).

Nonetheless, CRC remains a devastating disease since nearly $35-40 \%$ of all patients diagnosed will die from the disease (Fig.2). Accordingly, the expansion and the development of new path of therapy, like drugs specifically targeting the self-renewal of intestinal cancer stem cells - a tumor cell population from which CRC is supposed to relapse [12] remains relevant.

\begin{tabular}{|c|c|c|c|c|}
\hline Generic & Trade Name & Type & Class & Target \\
\hline - Capecitabine & Xeloda & small molecule & $\begin{array}{c}\text { antine oplastic } \\
\text { prodrug } \\
\text { (Fluorouracil) }\end{array}$ & $\begin{array}{c}\text { DNA } \\
\text { synthe sis }\end{array}$ \\
\hline Fluorouracil & $\begin{array}{l}\text { Efudex Adrucil } \\
\text { Fluoroplex }\end{array}$ & small molecule & antine oplastic & $\begin{array}{c}\text { DNA } \\
\text { synthe sis }\end{array}$ \\
\hline - Irinotecan & Camptosar & small molecule & $\begin{array}{c}\text { antineoplastic } \\
\text { prodrug } \\
\text { (Camptothecin) }\end{array}$ & $\begin{array}{c}\text { DNA } \\
\text { synthe sis }\end{array}$ \\
\hline Leucovorin & Wellcovorin & small molecule & $\begin{array}{c}\text { antine oplastic } \\
\text { adjunct }\end{array}$ & $\begin{array}{c}\text { DNA } \\
\text { synthesis }\end{array}$ \\
\hline Oxaliplatin & Eloxatin & small molecule & antine oplastic & $\begin{array}{c}\text { DNA } \\
\text { synthesis }\end{array}$ \\
\hline Aflibercept & Zaltrap & $\begin{array}{c}\text { Recombinant } \\
\text { protein }\end{array}$ & antiangiogenesis & VEGF \\
\hline Bevacizumab & Avastin & $\mathrm{mAb}$ & antiangiogene sis & VEGF \\
\hline - Cetuximab & Erbitux & $\mathrm{mAb}$ & antine oplastic & EGFr \\
\hline Panitumumab & Vectibix & $\mathrm{mAb}$ & antine oplastic & EGFr \\
\hline
\end{tabular}

Table 1. Anti-cancer colorectal drugs approved by the Food and Drug Administration. Drugs are presented sorted by type, i.e. small molecule or biologics (including recombinant protein and monoclonal antibody, noted mAb). Source: National Cancer Institute database, 2012. 


\subsection{Designing new therapies}

A classical approach of drug design in oncology is to identify modulators of specific signal transduction pathways that are important for tumor growth, survival, invasion, and metastasis. Because aberrant WNT signaling has been shown to drive the earliest step of colorectal tumorigenesis (see before), the WNT/ $\beta$-CATENIN pathway appears critical for CRC and therefore represents a target of choice for the development of CRC therapeutics.

\subsubsection{Oncogenic WNT/ $\beta$-CATENIN pathway as a therapeutic target}

Many experiments have demonstrated that disruption of the WNT signaling pathway lead to consistent growth inhibition and apoptosis of CRC cell lines and effective inhibition of tumor growth in CRC animal models. These results can be achieved by modulating the pathway at different levels, from the membrane receptor to the final nuclear transcription factors (Figure 3). A significant number of proof of principle studies have already been published, including targeted inhibition of WNT1-2, FZD or LRP5/6 receptors by antibodies or inhibitory fusion proteins [13-15], inactivation of the pathway by re-expression of WIF1 (WNT-inhibitory factor-1) or through restoration of tumor suppressors APC and Axin expression [16], expression of a dominant-negative mutant to block the transcription factor TCF4 [17], and finally direct inhibition of $\beta$-CATENIN using RNA interfering technologies in vitro and in vivo $[18,19]$. Taken together, these data provide a strong biological rationale for drugging the WNT/ $\beta$-CATENIN signaling pathway.

In addition, recent evidence also points to a role for WNT/ $\beta$-CATENIN signaling in the modulation of cancer stem cells. It is now well documented that a number of critical pathways regulating stem cell maintenance and normal developmental processes (e.g. HEDGEHOG-GLI, NOTCH, TGF) are also involved in the self-renewal and differentiation of cancer stem cells whose tumors are initiated [20]. Consequently, in a way similar to the HEDGEHOG-GLI pathway [21], a large number of high-throughput cell-based screening strategies, mainly designed to disrupt TCF/ $\beta$-CATENIN interaction, have led to the identification of promising molecules as inhibitors of WNT/ $\beta$-CATENIN pathway (reviewed by [22]).

However, currently few of these compounds have progressed beyond the preclinical stages. To date, the only compound designed to specifically disrupt $\beta$-CATENIN is developed for the treatment of Familial Adenomatous Polyposis (FAP), an inherited form of colon cancer. This new RNAi-based therapeutic known as CEQ508 consists of a modified E.coli bacterium that is able to express and deliver a shRNA to the epithelial cells of the gastrointestinal mucosa after ingestion by the patient [23]. CEQ508, which has shown efficiency in silencing $\beta$ CATENIN and preventing polyp formation in the APC ${ }^{\text {min }}$ FAP mouse model, is now in a Phase I clinical trial (Table 2).

Alternatively, a possible way of interfering with the WNT/ $\beta$-CATENIN cascade, even if not direct, may reside in the manipulation of KLF4 levels. KLF4 (Kruppel-like factor 4) is a tumor suppressor factor which is typically deficient in a variety of cancers, including colorectal cancer. In addition to controlling the cell cycle regulator cyclin D1, KLF4 has also been 
shown to inhibit the expression of $\beta$-CATENIN [24]. Therefore, the modulation of KLF4 expression may represent a novel therapeutic approach for $\beta$-CATENIN-driven malignancies. LOR-253 [25], a compound that stimulates KLF4 through the inhibition of the human metalregulatory transcription 1 (MTF1), is currently in a Phase I clinical study (Table 2).

It is noteworthy that despite the significance of this signaling axis for the treatment of sporadic colorectal cancer, none of the therapies engaged to date in CRC clinical trials are directly targeting WNT/ $\beta$-CATENIN pathway members. Nonetheless, considering the huge effort done at the research level to identify potential antagonists and the few candidate already engaged into preclinical studies, no doubt that innovative therapies will emerge from this promising pathway in a near future.

\subsubsection{Acquired tumor resistance and targeted therapies}

In the recent years, a cohort of oncogenes, including BRAF, KRAS, NRAS, PI3K, PTEN and SMAD4, have been found mutated in CRC with significant frequencies ranging from $6 \%$ (NRAS) to $40 \%$ (KRAS) [26]. These observations pinpoint one of the most challenging aspects of anticancer therapy that is intrinsic or acquired drug resistance. Indeed, several studies have shown that these mutations are associated with the lack of response to Cetuximab and Panitumumab (anti-EGFR therapies) observed in a subset of chemorefractory metastatic CRCs, suggesting that the corresponding deregulated signaling pathways are responsible for the occurrence of resistance of the tumor to the clinical treatment [27-28]. As a result, downstream key components (mostly protein kinases) of these constitutively activated growth-related signaling cascades have become targets for drug development. Small molecules inhibitors of BRAF (ARQ 736), MEK (Selumetinib, PD-0325901), PI3K (PX-866, BEZ235, BKM120), and MET (Tivantinib) that were able to reverse resistance to EGFR inhibitor therapy in pre-clinical studies [29-31] are currently in CRC Phase II clinical studies (Table 2). This new class of drugs appears therefore as a promising third-line therapeutic strategy for colon cancer patients, especially after recurrence of tumor resistance. However, a recent publication reporting the apparition of resistance to PI3K and AKT inhibitors mediated by $\beta$-CATENIN overactivation, may temper this enthusiasm. Depending on the tumor status, from proapoptotic tumor suppressor, PI3K or AKT inhibitors could become metastatic inducers [32]. Similar side effect induction mechanisms have also been reported in CRC for the BRAF(V600E) inhibitor Vemurafenib that triggers paradoxical EGFR activation [33]. All together, the complexity of these results supports the arrival of a personalized medicine, where a careful profiling of tumors will be useful to stratify patient population in order to test drugs sensitivity and combination with the ultimate goal to make treatments safer and more effective. 


\subsubsection{New anti-angiogenesis therapies}

As previously mentioned, until recently the humanized monoclonal antibody Bevacizumab against VEGF was the only anti-angiogenesis agent approved by FDA. It is now completed by Aflibercept, a recombinant protein consisting of the key domains of VEGF receptors 1 and 2. The compound captures and blocks all isoforms of VEGF-A and VEGF-B growth factors, as well as placental growth factors [34]. Due to improvement in the understanding of the critical role of angiogenesis in the maintenance of CRC tumors and the spread of their metastasis, anti-angiogenesis has become an area of active investigation [35]. However, the recent failure in Phase III first-line studies of two promising compounds (Sunitunib in 2009 and Cediranib in 2010) has cast serious doubt on that strategy. Therefore, the approval of Aflibercept provides timely support to the further development of anti-angiogenics as treatment for metastatic CRC. Today, 4 additional therapeutic agents that target VEGF, Ramucirumab [36], Icrucumab [37], Regorafenib [38] and Vatalanib [39-40] are under clinical evaluation (Table 2). This battery of anti-angiogenics is supplemented by AMG386, a recombinant peptide-antibody fusion protein (peptibody) which targets another signaling pathway involved in tumoral angiogenesis, the angiopoietin axis [41]. AMG386, which inhibits the interaction between the ligands ANGIOPOIETIN-1 and ANGIOPOIETIN-2 with their TIE2 receptor, is currently in Phase II. Finally, a phase III trial was also recently initiated (May 2012) to evaluate TAS-102, a combination agent composed of the cytotoxic pyrimidine analog TFT and a thymidine phosphorylase inhibitor (TPI) with antineoplastic activity (Table 2). TAS-102 mechanism of action is based on the inhibition of the thymidine phosphorylase (TYMP) also known as the platelet-derived endothelial cell growth factor, a potent angiogenic factor [42]. In this context, it is important to point out that differences in the efficiency to block angiogenesis and tumor progression have been observed between preclinical models and clinical trials, when comparing antibodies with small molecules [35]. These discrepancies in clinical outcome underline the necessity to validate compounds on relevant models, preferentially based on human tissues, very early during drug development process.

\subsubsection{Other cellular mechanisms under target}

Modifications in the epigenetic landscape are commonly associated with cancer, but on the contrary to genetic mutations, these changes are potentially reversible and therefore druggable. Most of the epigenetic drugs discovered to date modulate DNA methylation or histone acetylation. Four epigenetic drugs have already been approved by FDA for use in clinic against various cancers. An additional one, the histone deacetylase (HDAC) inhibitor Resminostat [43] is currently being studied in patients with CRC, in a phase I/II trial (Table 2). 


\begin{tabular}{|c|c|c|c|c|}
\hline Drug & Company & Type & Target & Status \\
\hline ARQ 736 & ArQule & small molecule & BRAF & Phase I \\
\hline Selumetinib & Array BioPharma & $"$ & MEK & Phase II \\
\hline PD-0325901 & Pfizer & $"$ & MEK & Phase I \\
\hline PX-866 & Oncothyreon & $"$ & $\mathrm{PI} 3 \mathrm{~K}$ & Phase II \\
\hline BEZ235 & Novartis & $"$ & $\mathrm{PI} 3 \mathrm{~K}$ & Phase I \\
\hline - BKM120 & Novartis & $"$ & $\mathrm{PI} 3 \mathrm{~K}$ & Phase II \\
\hline Tivantinib & ArQule & $"$ & MET & Phase II \\
\hline Brivanib & BMS & $"$ & $\begin{array}{l}\text { VEGFR2 } \\
\text { PDGFR } \beta \\
\end{array}$ & Phase III \\
\hline Regorafenib & Bayer & $"$ & $\begin{array}{c}\text { VEGFR2-3 } \\
\text { PDGFR } \\
\text { FGFR } \\
\end{array}$ & Phase III \\
\hline Vatalanib & Bayer / Novartis & $"$ & VEGFR1-3 & Phase III \\
\hline LOR-253 & Lorus Therapeutics & $"$ & MTF1 inhibitor & Phase I \\
\hline - TAS-102 & Taiho Pharma & $"$ & TYMS TYMP & Phase III \\
\hline Resminostat & $4 \mathrm{SC}$ & $"$ & HDAC inhibitor & Pasel/II \\
\hline CEQ508 & Marina Bio & $\begin{array}{l}\text { biologics } \\
\text { (shRNA) }\end{array}$ & $\beta$ CATENIN & Phase I/II \\
\hline - Icrucumab & ImClone Systems & $\begin{array}{c}\text { biologics } \\
\text { (humanized } \mathrm{mAb} \text { ) }\end{array}$ & VEGFR-1 & Phase II \\
\hline Ramucirumab & ImClone Systems & $"$ & VEGFR-2 & Phase II \\
\hline AMG 386 & Amgen & $\begin{array}{c}\text { biologics } \\
\text { (peptibody) }\end{array}$ & Tie-2R & Phase II \\
\hline$>\mathrm{GL}-\mathrm{ONC1}$ & Genelux & $\begin{array}{c}\text { biologics } \\
\text { (oncolytic virus) }\end{array}$ & Tumoral cells & Phase I/II \\
\hline ColoAd1 & PsiOxus & $"$ & $"$ & Phase I/II \\
\hline - NV1020 & Medigene & $"$ & $"$ & Phasell \\
\hline Reolysin & Oncolytics & $"$ & $"$ & Phase I/II \\
\hline JX594 & Jennerex & $"$ & $"$ & Phase I/II \\
\hline
\end{tabular}

Table 2. Anti-cancer drugs in colorectal clinical trials. This table gives an overview of the main colorectal cancer therapies being currently evaluated in clinical trials. Drugs are presented sorted by type, i.e. small molecule or biologics. For each compound, the pathway target and clinical status is provided. Source: National Cancer Institute database, 2012 and the clinical database of the Journal of Gene Medicine (http://www.wiley.com/legacy/wileychi/genmed/clinical).

\subsubsection{Unconventional approaches}

Oncolytic viral therapy represents an appealing alternative therapeutic strategy for the treatment of CRC, both as single agent or in combination with existing clinical regimens. Oncolytic viruses, like the vaccinia virus (a virus previously used for worldwide vaccination against smallpox), have the property to selectively infect and destroy tumor cells with limited or no toxicity to normal tissues. These viruses efficiently replicate in tumor tissue, cause 
tumor lyses and stimulate antitumor immune response. During the last decade, numerous mutants have been engineered to improve their tumor specificity and antitumor efficacy, and to allow tracking of viral delivering by non-invasive imaging [44]. No less than five oncolytic virotherapies are currently evaluated in clinical trials for metastatic CRC indication, including ColoAd1, derived from an adenovirus [45], NV1020, derived from an Herpes simplex virus [46], Reolysin, a reovirus [47], and JX-594 [48] and GL-ONC1 [49] both derived from vaccinia viruses, reflecting the many hopes carried by this emerging treatment modality. However, it is noteworthy to mention that there are still some difficulties to viral infection. Solid tumors have a complex microenvironment that includes disorganized surrounding stroma, poor vascular network as well as high interstitial fluid pressure. All these parameters will limit viral delivery since viral penetration directly depends on cellular packing density and adhesion between cancer cells [50]. Moreover, hypoxia reduces viral replication, and therefore oncolytic efficiency, without affecting tumoral cells viability [51]. These observations highlight how choosing the right experimental validation model, e.g. 3D cell cultures or spheroids in vitro, or patient primary-derived xenografts that retain tumoral architecture complexity in vivo, will be critical for future clinical success.

This inventory of new drugs for the treatment of colorectal cancer highlights the diversity of approaches being considered to combat the disease. Whether based on small molecules, humanized antibodies or modified viruses, their success in further clinical assessment is largely related to the quality of their preclinical evaluation. This is why both the choice of appropriate existing model systems and the development of more clinically relevant and predictive pre-clinical models appear critical in overcoming the high attrition rates of compounds entering clinical trials.

Current research is also focusing on the development of biomarkers that will be useful for the early detection of $\mathrm{CRC}$, as well as for fine-tuning drug regimen and following efficacy during trials and treatments. To date, only a few markers have been recommended for practical use in clinic [52] but large-scale genomics technology combined with advanced statistical analyses should generate soon new biomarker panels for CRC diagnosis [53]. Then, it will be interesting to see how these biomarkers could be implemented in preclinical stages to improve drug selection.

\section{Preclinical models}

\subsection{Colon cancer cell lines}

It is worth mentioning that most of our understanding of the molecular mechanisms involved in CRC come from studies done on mouse or human cell lines that represent only a highly selected fraction of the original tumor and that may have acquired in vitro additional genetic abnormalities. Moreover, isolated cells grown on plastic dish flooded with growth factors appear retrospectively as a very poor model system to elucidate human CRC biolo- 
gy, especially with regard to the importance of growth signaling pathways (EGF/FGF) and tumor/stroma interactions in CRC progression. Clearly, the scientific community has taken into account these limitations, as shown by the growing interest for more complex models (e.g. 3D spheroids). However, although imperfect, colon cancer cell lines still represent a unique resource that can be extremely valuable in term of genetic manipulation and highthroughput screening, with cell viability, cell proliferation or promoter specific reporter activity being the usual endpoints followed. Several initiatives have been launched to maximize their utility in large scale drug discovery programs.

\subsubsection{NCI-60 cancer cell lines collection}

The NCI60 is a collection of 59 human cancer cell lines derived from diverse tissues, including colon (HT-29, COLO-205, HCT-15), which was established in the early 1990s by the Sanger institute (http://www.sanger.ac.uk/genetics/CGP/NCI). In an attempt to identify new active molecules, over 100,000 chemical compounds were pharmacologically tested in this cell line set. But disappointingly, most of the selected positive candidates were typical cytotoxics, affecting cancer cells via general fundamental cellular processes, like cell cycle regulation. These cell lines are under further characterization by sequencing for mutations in known human oncogenes. Interestingly, this resource can be screened on demand for any chemical or biological agent. As an example, the NCI60 has been recently used to determine the permissivity of standard cancer cell lines to VACV infection and replication, with the aim to better characterize viral oncolytic therapeutic strategies [54].

\subsubsection{The Cancer Genome Project}

The emergence of tumor acquired resistance to pharmacological inhibitors linked to mutations in driver oncogenes has recently revived the interest for cancer cell lines. Indeed, an extensive characterization of cell lines at the genomic and genetic levels will allow determining a genetic profile predictive of drug sensitivity. Such a signature will help to stratify patient population and identify efficient therapeutics combination, as long as cell lines reflect real tumor biology. In this perspective, the Sanger Cancer Institute has started the genetic characterization of a panel of 800 cancer cell lines (The Cancer Genome Project, http:// www.sanger.ac.uk/genetics/CGP). Using current high throughput techniques this program intends to provide information on mutations, copy number variations, single nucleotide polymorphisms (SNPs) and microsatellite instability of usual cancer cell lines.

\subsubsection{The Cancer Cell Line Encyclopedia}

Similarly, the cancer cell line encyclopedia project is a joint initiative between The Novartis Institutes for Biomedical research and scientists from the Broad Institute (http://www.broadinstitute.org/ccle/home) to provide a detailed genetic and pharmacologic characterization of a panel of 1000 human cancer cell lines, including more than 60 CRC cell lines. Again, the ultimate purpose of this project is to establish genetic maps that would predict anticancer drug sensitivity [55]. 


\subsubsection{Biomimetic cell culture models}

The derivation of a cancer cell line from the primary tumor is not an obvious process, and for many cancers, few if any cell line can be obtained. A success rate of less than $10 \%$ has been reported for the establishment of human colon cancer cell lines grew immediately in vitro from fresh tumors [56]. Elasticity of the surrounding microenvironment has been pointed out as a critical parameter of in vitro cell growth. Indeed, culture plastic dishes are much more rigid than the epithelial wall of the intestine (10000 kPa vs $40 \mathrm{kPa})$. More importantly, depending on the stiffness of the substrate, cells can be differentially sensitive to drugs in term of spreading and apoptosis-induction, notably because of the expression and presentation of surface receptors [57]. Therefore, the choice of an appropriate biomimetic substrate that will preserve the in vivo phenotype appears decisive not only for cell survival but also for clinical relevance. Soft polymer surface, with different degrees of stiffness reproducing the original tumor environment have been engineered (ExCellness Biotech) and are now available to improve $2 \mathrm{D}$ or $3 \mathrm{D}$ cultures.

\subsubsection{Colon cancer stem cell models}

Cancer stem cells (CSCs) are a discrete self-renewing tumor cell subpopulation that can differentiate into multiple lineages, drive tumor growth and metastasis. Moreover, CSCs are thought to be responsible for tumor recurrence after chemotherapy and radiotherapy. One of the characteristic of the CSCs is their ability to form spherical cell colonies when they are cultured in chemically defined serum-free medium at a relative low density [58]. This model, also called colonospheres, constitutes a unique in vitro system to elaborate therapeutic strategies that specifically target colon CSCs, like oncolytic adenoviruses developed to target specific CSCs antigens (e.g. CD44 or LGR5). In addition, sorting of CSCs based on specific surface epitopes expression has also been used to enrich culture in tumor initiating cells in order to increase the success rate of cell line establishment and therefore improve cell line representation for CRC.

\subsection{Multicellular Spheroid models}

Early stage development of novel anti cancer treatment requires in vitro methods able to deliver fast, reliable and predictive results. To select the most active molecule lead in a library, pharmaceutical industry has turned its attention to High Throughput Screening (HTS) tests which mimic human tissues. Furthermore, 3-Dimensional (3D) test system has been widely accepted as being more informative and relevant than classical 2D cell systems. Combination of HTS and 3D models such as the multicellular tumor spheroid model has been pointed out having the potential to increase predictability of clinical efficacy from in vitro validation therefore contributing savings in both development cost and time [59]. Advantages of spheroids compared to classical 2D cell line culture have been reported [60]. Indeed, proteomic analysis of multicellular spheroids versus monolayers cultures identifies differential protein expression relevant to tumor cell proliferation, survival, and chemoresistance. 
Consequently, spheroids strategy has been used for the screening of new anticancer agents, like compounds that modulate apoptosis pathways [61].

Standardized spherical microtissue production in a 96 or 384-well hanging-drop multiwell plate format on robotic platform has been successfully achieved by 3D Biomatrix and Insphero AG. Formation of standardized spheroids rely on the use of A431.H9, a human epithelial carcinoma cells, [62] or the colon cancer cell line HCT116 [63]. Interestingly, loss of cancer drug activity in HCT-116 cells during spheroid formation in a 3D spheroid cell culture system has been reported [64]. Spheroid cell models also enable the study of colon cancer chemoresistance and metastasis [65].

\subsection{Colon cancer animal models}

\subsubsection{Chemically induced animal models}

Colon cancer can be induced in mouse by specific carcinogens like 1,2-dimethylhydrazine $(\mathrm{DMH})$ and azoxymethane (AOM). Exposure of the mouse intestine to these chemicals triggers rapid and reproducible tumor induction which recapitulates the adenoma-carcinoma sequence that occurs in human sporadic CRCs, with the notable exception however of the invasive and metastatic stage. The application of colon carcinogenesis treatment to CRC mouse model, like the Apc $\mathrm{Ain}^{\mathrm{+}}$ animals, results in an increased tumor incidence by up to 6 fold. Interestingly, differences in genetic mutations that arise in chemically induced colon tumor models are largely carcinogen specific. K-Ras mutations are predominant in the DMH model, while AOM treated mice exhibit tumors with activating mutations in the $\beta$-catenin gene [66]. These models could therefore be useful to assess therapies targeting specific CRC signaling axis.

\subsubsection{Apc ${ }^{\mathrm{min} /+}$ mice}

The multiple intestinal neoplasia (Min) mouse was identified following random mutagenesis with ethylnitrosourea [67]. A mutation in the Apc gene was identified as the cause of the disease, like in the human Familial Adenomatous Polyposys (FAP). However, Although $\mathrm{Apc}^{\mathrm{min} /+}$ mice spontaneously form a large number of benign adenomas in the small intestine, colon tumors develop in fewer than half of the animals, in contrast to human FAP patients which routinely develop invasive carcinomas.

\subsubsection{Genetically Engineered Mouse models (GEMs)}

The main purpose for developing genetically engineered mice is to model the human disease in order to first better understand the biological processes underlying normal and malignant cell physiology, and second to establish a reliable preclinical model mimicking the true biology of human cancer and useful for drug discovery. In an attempt to accurately model the phenotype observed in FAP or sporadic CRC patients, a constellation of Apc genetically engineered mice, all based on the loss of the wild-type Apc allele, have been creat- 
ed (see [68] for review). To date, GEMs have been extensively used to demonstrate the function of candidate genes in CRC tumorigenesis, and the fact that tumors occur and develop naturally in the host constitutes undeniably an advantage of transgenic models compare to xenograft models.

The main disadvantage, except the time and the cost required to generate and maintain such animals, lies in the fact that none of these Apc mouse models consistently display metastasis, while treating metastasis is the current challenge.

\subsection{Xenograft Models}

The development of cancer xenograft models allows in vivo testing required for the predictive assessment of the clinical tolerability and efficacy of therapeutic agents. For decades, xenografts have been generated from human tumor cell lines that have been selected by in vitro culture.

\subsubsection{Subcutaneous xenografts}

As standard, tumor cells are implanted subcutaneous in the hindflank region of immunodeficient mice (e.g. Nude, NSG) to prevent rejection. Tumor growth during the treatment period is monitored either by measuring the tumor mass on the animals using Vernier calipers or by recording the activity of specific markers, like luminescent (Luciferase) or fluorescent (GFP) reporters, using non invasive imaging. At the end of the experiment, animals are euthanized and tumors are collected for histological or genetic analyses. Many applications are possible: complex growth competition assays can be performed inside a same tumor by injecting a mix of genetically modified tumor cell population, each expressing a specific reporter (Red/ Green assay). These assays allow the identification of new oncogenic targets, revealed by growth advantage, and therefore critical for tumor development [69]. Subcutaneous xenografts are useful for the study of tumor / stroma / vascular network interactions, which is not possible in cell lines. Nonetheless, this heterotypic human/mouse model has its limitations since some murine ligands are not able to activate human receptors (e.g. HGF/MET, [70]). In addition, some CRC cell lines, even if implanted subcutaneous, can produce distant metastasis to the lung or the lymphatic nodes, allowing to study the effect of therapies specifically designed against metastatic dissemination and growth (C. Mas, pers. comm.).

Here it is interesting to note that at the preclinical level, the in vivo antiangiogenic activity of Sunitinib (see "New anti-angiogenesis therapies" section before) was evaluated in sub-cutaneous xenograft tumor models derived from HT29 and Colo205 human colon carcinoma cell lines implanted in athymic mice [71-72]. However, thereafter no advantage in anti-tumor efficacy could be shown in Phase III trial. Although the reasons for this failure are not clearly established, the genetic heterogeneity observed in primary CRC patient tumors could explain this lack of efficacy: in vitro selected cell lines are not enough representative of CRC patient's tumors. This observation suggests that new models including large tumor panels 
able to recapitulate the biological heterogeneity of patient's populations appear necessary for an accurate evaluation of molecular targeted agents.

\subsubsection{Orthotopic xenografts}

A number of observations suggest that the behavior of tumor cells can be significantly different when implanted as a subcutaneous xenograft, compared to their behavior when grown into the tissue of origin. For these reasons, orthotopic models are thought to be better predictors of drug efficacy and are more clinically relevant. To this purpose, intracolonic xenografts have been developed. Technically, a small incision is made in the abdomen of the immunodeficient mouse, directly over the colon, and CRC cells are implanted under the serosa of the colon. Local tumor growth on the colon is then monitored. Although more realistic, the use of orthotopic xenograft models does not guarantee success. The efficacy of Semaxanib, an antiangiogenic molecule, has been tested in preclinical stages using an intracolonic Xenograft [73] but compound development was stopped after negative results from Phase III. Again, representation of patient heterogeneity should be taken into account at the preclinical level.

Finally, if the use of selected tumor lines and the value of the mouse as a host could be questionable in xenograft models, the response end points, survival end points, and tumor cell killing end points that are usually used during in vivo efficacy studies remain in line with clinical investigations.

\subsubsection{Patient-derived xenograft models (PDXs)}

In order to circumvent the difficulties of establishing new cell lines, as well as to establish an in vivo model preserving the histopathological characteristics of the original tumor, investigators have developed a new xenograft system based on the direct grafting of human tumor fragment into immunodeficient mice (Figure 4). Several CRC patient-derived xenograft collections (PDX) have been reported, with an average tumor take rate of over 60\% [56, 74-75]. They can be cryopreserved and re-established in mice as needed, or maintained as xenografts from mice to mice. Intensive characterization has demonstrated that the architecture of PDX tumors, their gene expression profile and their chromosomal instability remains very similar to the parental tumor, even after successive passages [75-76]. Importantly, high correlation between drug activity in PDX and clinical outcome has been reported, making this model a valuable pharmacological tool for drug development [74-75]. Moreover, because they are derived from tumor fragment, PDX tumors retains the genetic heterogeneity existing in the original human tumor and are therefore useful for studies exploring acquired drug resistance mechanisms [75, 77]. The use of PDX as a model for tumor-stroma interaction is however less obvious since by the fourth passages human tumor stroma is replaced by the murine host [75]. All together, the above considerations highlight the potential of the PDX model to accelerate drug development and predictive biomarker discovery in CRC. 


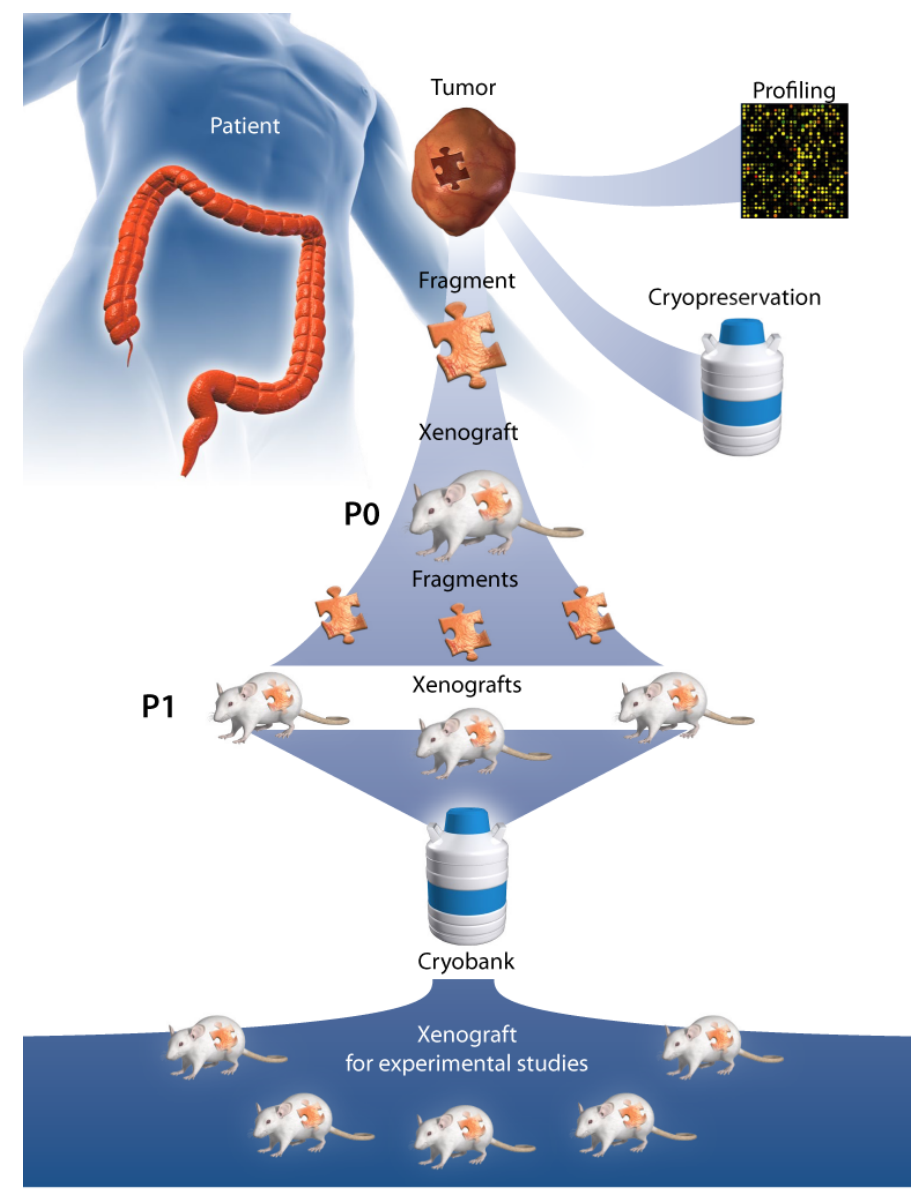

Figure 4. The PDX model. Sequential steps leading to the establishment of a CRC primary Patient-Derived Tumor Xenograft collection. Briefly, a CRC tumor fragment coming from surgical waste is directly xenografted in an immunodeficient mouse (Passage 0). After successful engraftment, new fragments are taken from the mouse hosted human tumor and xenografted again in multiple immunodeficient mice (Passage 1). A collection of fragments from the resulting tumors can then be cryopreserved in a tissue bank for subsequent experiments or directly re-engrafted in mice for expansion (P2, P3, etc...). At any step, tumor fragments can be analyzed and compared to the parental tumor in terms of gene expression, genetic mutations, genomic stability or histopathological features.

\subsection{Ex-Vivo Organotypic Culture models (EVOCs)}

As previously mentionned, current 2D monolayer culture systems are not enough predictive of in vivo tumor behavior. Indeed, 3D environement is required to provide essential signaling necessary for establishing and maintaining tumor specific morphogenic programs. Thus, 
an ex vivo methodology which can recapitulate physiological processes and generate multiple experimental replicates from a single tumor, saving at the same time animals involved in in vivo experiments will be of great benefit. Ex vivo organotypic cultures (EVOCs), by preserving the original cancer microenvironement (e.g. epithelial-stromal interaction) fulfill this requirement. Recently, a number of culture methods have been perfected leading to the development of breast, lung, liver and colon EVOC tumor models [78-81]. EVOCs allow the evaluation of tumor morphology, proliferation, viability and resistance to therapy in vitro. Moreover, differential gene-expression profiling across tumor and stroma compartments can be performed, without any contamination coming from a murine host as seen in xenograft models [78]. Recent observations have shown that CRC EVOCs mimic closely the in vivo situation, at the immunohistochemical level [81], but also in term of oncogenic pathway fonctionallity and pharmacodynamic properties [78]. Importantly, dose-response experiments with the PIK3 inhibitor LY294002 demonstrate that CRC EVOCs may be used to predit tumor sensitivity to drugs in a patient-specific manner [78]. EVOCs represent therefore a highly promising in vitro tumor model, when combined with automated medium-throughput analyses, has the potential to significantly enhance preclinical drug evaluation studies.

\section{Conclusion}

The development of relevant and predictive models is key to increase the quality of preclinical researches and to increase the success rate of new drugs. Many progresses have been made in this area to get as closer as possible to in vivo situations of human CRC cancers. Even though cell lines and animal models are still indispensable, the Xenograft Models, EVOCs as well as the 3D culture of CRC cancer cells hold the promises for the development of new, more efficient and safer drugs.

\section{Author details}

Samuel Constant, Song Huang, Ludovic Wiszniewski and Christophe Mas*

*Address all correspondence to: christophe.mas@oncotheis.com

OncoTheis, 14 Chemin des aulx, CH-1228 Plan-les-Ouates, Geneva, Switzerland

\section{References}

[1] Scannell, J. W., Blanckley, A., Boldon, H., \& Warrington, B. (2012). Diagnosing the decline in pharmaceutical R\&D efficiency. Nat Rev Drug Discov, 11, 191-200.

[2] Arrowsmith, J. (2011a). Trial watch: Phase II failures: 2008-2010. Nat Rev Drug Discov, 10, 328-9. 
[3] Arrowsmith, J. (2011b). Trial watch: phase III and submission failures: 2007-2010. Nat Rev Drug Discov, 10, 87.

[4] Mayr, L. M., \& Fuerst, P. (2008). The future of high-throughput screening. J Biomol Screen.; , 13, 443-8.

[5] Groden, J., Thliveris, A., Samowitz, W., Carlson, M., Gelbert, L., Albertsen, H., Joslyn, G., Stevens, J., Spirio, L., Robertson, M., et al. (1991). Identification and characterization of the familial adenomatous polyposis coli gene. Cell, 66, 589-600.

[6] Powell, S. M., Zilz, N., Beazer-Barclay, Y., Bryan, T. M., Hamilton, S. R., Thibodeau, S. N., Vogelstein, B., \& Kinzler, K. W. (1992). APC mutations occur early during colorectal tumorigenesis. Nature, 359, 235-7.

[7] Clevers, H., \& Nusse, R. (2012). Wnt/ $\beta$-catenin signaling and disease. Cell, 149, 1192-205.

[8] Morin, P. J., Sparks, A. B., Korinek, V., Barker, N., Clevers, H., Vogelstein, B., \& Kinzler, K. W. (1997). Activation of beta-catenin-Tcf signaling in colon cancer by mutations in beta-catenin or APC. Science, 275, 1787-90.

[9] Howlader, N., Noone, A. M., Krapcho, M., Neyman, N., Aminou, R., Altekruse, S. F., Kosary, C. L., Ruhl, J., Tatalovich, Z., Cho, H., Mariotto, A., Eisner, M. P., Lewis, D. R., Chen, H. S., Feuer, E. J., \& Cronin, K. A. (2012). SEER Cancer Statistics Review, 1975Vintage 2009 Populations). National Cancer Institute.

[10] Zavoral, M., Suchanek, S., Zavada, F., Dusek, L., Muzik, J., Seifert, B., \& Fric, P. (2009). Colorectal cancer screening in Europe. World J Gastroenterol, 15, 5907-5915.

[11] Gaya, A., \& Tse, V. (2012). A preclinical and clinical review of aflibercept for the management of cancer. Cancer Treat Rev, 38, 484-93.

[12] Merlos, Suárez., et al. (2011). The Intestinal Stem Cell Signature Identifies Colorectal Cancer Stem Cells and Predicts Disease Relapse. Cell Stem Cell, 8, 511-24.

[13] He, B., You, L., Uematsu, K., Xu, Z., Lee, A. Y., Matsangou, M., Mc Cormick, F., \& Jablons, D. M. (2004). A monoclonal antibody against Wnt-1 induces apoptosis in human cancer cells. Neoplasia, 6, 7-14.

[14] You, L., He, B., Xu, Z., Uematsu, K., Mazieres, J., Fujii, N., Mikami, I., Reguart, N., Mc Intosh, J. K., Kashani-Sabet, M., Mc Cormick, F., \& Jablons, D. M. An anti-Wnt-2 monoclonal antibody induces apoptosis in malignant melanoma cells and inhibits tumor growth. Cancer Res, 64(15), 5385-9.

[15] De Almeida, V. I., Miao, L., Ernst, J. A., Koeppen, H., Polakis, P., \& Rubinfeld, B. (2007). The soluble wnt receptor Frizzled8CRD-hFc inhibits the growth of teratocarcinomas in vivo. Cancer Res, 67, 5371-9, Taniguchi H, Yamamoto H, Hirata T, Miyamoto N, Oki M, Nosho K, Adachi Y, Endo T, Imai K, Shinomura Y. '05 Frequent epigenetic inactivation of Wnt inhibitory factor- 1 in human gastrointestinal cancers. Oncogene.; 24:7946-52. 
[16] Morin, P. J., Sparks, A. B., Korinek, V., Barker, N., Clevers, H., Vogelstein, B., \& Kinzler, K. W. (1997). Activation of beta-catenin-Tcf signaling in colon cancer by mutations in beta-catenin or APC. Science, 275(5307), 1787-90.

[17] Van de Wetering, M., Sancho, E., Verweij, C., de Lau, W., Oving, I., Hurlstone, A., van der Horn, K., Batlle, E., Coudreuse, D., Haramis, A. P., et al. (2002). The $\beta$-catenin/TCF-4 complex imposes a crypt progenitor phenotype on colorectal cancer cells. Cell, 111, 241-250.

[18] Verma, U. N., Surabhi, R. M., Schmaltieg, A., Becerra, C., \& Gaynor, R. B. (2003). Small interfering RNAs directed against beta-catenin inhibit the in vitro and in vivo growth of colon cancer cells. Clin Cancer Res, 9, 1291-300.

[19] Scholer-Dahirel, A., Schlabach, M. R., Loo, A., Bagdasarian, L., Meyer, R., Guo, R., Woolfenden, S., Yu, K. K., Markovits, J., Killary, K., Sonkin, D., Yao, Y. M., Warmuth, M., Sellers, W. R., Schlegel, R., Stegmeier, F., Mosher, R. E., \& Mc Laughlin, M. E. (2011). Maintenance of adenomatous polyposis coli (APC)-mutant colorectal cancer is dependent on Wnt/beta-catenin signaling. Proc Natl Acad Sci U S A, 108, 17135-40.

[20] Van der Flier, L. G., \& Clevers, H. (2009). Stem cells self-renewal, and differentiation in the intestinal epithelium. Annu Rev Physiol, 71, 241-60.

[21] Mas, C., Ruiz, i., \& Altaba, A. Small molecule modulation of HH-GLI signaling: current leads, trials and tribulations. Biochem Pharmacol, 80, 712-23.

[22] Takahashi-Yanaga, F., \& Kahn, M. Targeting Wnt signaling: can we safely eradicate cancer stem cells? Clin Cancer Res, 6(12), 3153-62, 2010 Jun 8.

[23] Vaze, M. B., Wu, T. S., Shaguna, Templin. M., \& Polisky, B. Engineering of trans kingdom RNAi (tkRNAi) against gastrointestinal polyps. Cancer Research, 72(8, 1).

[24] Zhang, N., Zhang, J., Shuai, L., Zha, L., He, M., Huang, Z., \& Wang, Z. Krüppel-like factor 4 negatively regulates $\beta$-catenin expression and inhibits the proliferation, invasion and metastasis of gastric cancer. Int J Oncol, 40(6), 2038-48.

[25] Cukier, H., Peralta, R. , Hongnan, J. , Huesca, M., Yoon, L., \& Aiping, Y. (2012). Preclinical dose scheduling studies of LOR-253, a novel anticancer drug, in combination with chemotherapeutics in lung and colon cancers. Annual Meeting of the American Association for Cancer Research; Chicago, IL. Philadelphia (PA): AACR; Cancer Res, 72(8), Abstract nr 3710.

[26] Forber, S. A., et al. (2011). COSMIC: mining complete cancer genomes in the Catalogue of Somatic Mutations in Cancer. Nucleic Acids Res, 39, D945-50.

[27] Sartore, Bianchi., et al. (2009). PIK3CA mutations in colorectal cancer are associated with clinical resistance to EGFR-targeted monoclonal antibodies. Cancer Res, 69, 1851-7. 
[28] De Roock, W., De Vriendt, V., Normanno, N., Ciardiello, F., \& Tejpar, S. (2011). KRAS, BRAF, PIK3CA, and PTEN mutations: implications for targeted therapies in metastatic colorectal cancer. Lancet Oncol, 12, 594-603.

[29] Mueller, A., Bachmann, E., Linnig, M., Khillimberger, K., Schimanski, C. C., Galle, P. R., \& Moehler, M. (2012). Selective PI3K inhibition by BKM120 and BEZ235 alone or in combination with chemotherapy in wild-type and mutated human gastrointestinal cancer cell lines. Cancer Chemother Pharmacol, 69, 1601-15.

[30] Misale, , et al. (2012). Emergence of KRAS mutations and acquired resistance to antiEGFR therapy in colorectal cancer. Nature, 486, 532-6.

[31] Munshi, N., Jeay, S., Li, Y., Chen, C. R., France, Ashwell. DS, et al. (2010). ARQ 197, a novel and selective inhibitor of the human c-Met receptor tyrosine kinase with antitumor activity. Mol Cancer Ther, 9, 1544-53.

[32] Tenbaum, S. P., et al. (2012). $\beta$-catenin confers resistance to PI3K and AKT inhibitors and subverts FOXO3a to promote metastasis in colon cancer. Nat Med, 18, 892-901.

[33] Prahallad, A., Sun, C., Huang, S., Di Nicolantonio, F., Salazar, R., Zecchin, D., Beijersbergen, R. L., Bardelli, A., \& Bernards, R. (2012). Unresponsiveness of colon cancer to BRAF(V600E) inhibition through feedback activation of EGFR. Nature, 483(7387), 100-3.

[34] Holash, J., Davis, S., Papadopoulos, N., Croll, S. D., Ho, L., Russell, M., Boland, P., Leidich, R., Hylton, D., Burova, E., Ioffe, E., Huang, T., Radziejewski, C., Bailey, K., Fandl, J. P., Daly, T., Wiegand, S. J., Yancopoulos, G. D., \& Rudge, J. S. (2002). VEGFTrap: a VEGF blocker with potent antitumor effects. Proc Natl Acad Sci, 99, 11393-11398.

[35] Ferrarotto, R., \& Hoff, P. M. (2012). Antiangiogenic Drugs for Colorectal Cancer: Exploring New Possibilities. Clin Colorectal Cancer, in press.

[36] Spratlin, J. L., Cohen, R. B., Eadens, M., et al. (2010). Phase I pharmacologic and biologic study of ramucirumab (IMC-1121B), a fully human immunoglobulin G1 monoclonal antibody targeting the vascular endothelial growth factor receptor-2. J Clin Oncol, 28, 780-7.

[37] Schwartz, J. D., Rowinsky, E. K., Youssoufian, H., Pytowski, B., \& Wu, Y. (2010). Vascular endothelial growth factor receptor-1 in human cancer: concise review and rationale for development of IMC-18F1 (Human antibody targeting vascular endothelial growth factor receptor-1). Cancer, 116(4), 1027-32.

[38] Grothey, A., Sobrero, A. F., Siena, S., et al. (2012). Results of a phase III randomized, double-blind, placebo-controlled, multicenter trial (CORRECT) of regorafenib plus best supportive care (BSC) versus placebo plus BSC in patients (pts) with metastatic colorectal cancer (mCRC) who have progressed after standard therapies. J Clin Oncol, 30(4), abstract LBA385. 
[39] Hecht, J. R., Trarbach, T., Hainsworth, J. D., Major, P., Jäger, E., Wolff, R. A., LloydSalvant, K., Bodoky, G., Pendergrass, K., Berg, W., Chen, B. L., Jalava, T., Meinhardt, G., Laurent, D., Lebwohl, D., \& Kerr, D. (2011). Randomized, placebo-controlled, phase III study of first-line oxaliplatin-based chemotherapy plus PTK787/ZK 222584, an oral vascular endothelial growth factor receptor inhibitor, in patients with metastatic colorectal adenocarcinoma. J Clin Oncol, 29, 1997-2003.

[40] Van Cutsem, E., Bajetta, E., Valle, J., Köhne, C. H., Hecht, J. R., Moore, M., Germond, C., Berg, W., Chen, B. L., Jalava, T., Lebwohl, D., Meinhardt, G., Laurent, D., \& Lin, E. (2011). Randomized, placebo-controlled, phase III study of oxaliplatin, fluorouracil, and leucovorin with or without PTK787/ZK 222584 in patients with previously treated metastatic colorectal adenocarcinoma. J Clin Oncol, 29, 004-10.

[41] Neal, J., \& Wakelee, H. (2010). AMG-386, a selective angiopoietin-1/-2-neutralizing peptibody for the potential treatment of cancer. Curr Opin Mol Ther, 12, 487-95.

[42] Temmink, O. H., Emura, T., de Bruin, M., Fukushima, M., \& Peters, G. J. (2007). Therapeutic potential of the dual-targeted TAS-102 formulation in the treatment of gastrointestinal malignancies. Cancer Sci, 98, 779-89.

[43] Mandl-Weber, S., Meinel, F. G., Jankowsky, R., Oduncu, F., Schmidmaier, R., \& Baumann, P. (2010). The novel inhibitor of histone deacetylase resminostat (RAS2410) inhibits proliferation and induces apoptosis in multiple myeloma (MM) cells. $\mathrm{Br} J$ Haematol, 149, 518-28.

[44] Russell, S. J., Peng, K. W., \& Bell, J. C. (2012). Oncolytic virotherapy. Nat Biotechnol, $30,658-670$.

[45] Kuhn, I., Harden, P., Bauzon, M., Chartier, C., Nye, J., Thorne, S., Reid, T., Ni, S., Lieber, A., Fisher, K., Seymour, L., Rubanyi, G. M., Harkins, R. N., \& Hermiston, T. W. (2008). Directed evolution generates a novel oncolytic virus for the treatment of colon cancer. PLoS One, 3, e2409.

[46] Geevarghese, S. K., Geller, D. A., de Haan, H. A., Hörer, M., Knoll, A. E., Mescheder, A., Nemunaitis, J., Reid, T. R., Sze, D. Y., Tanabe, K. K., \& Tawfik, H. (2010). Phase I/II study of oncolytic herpes simplex virus NV1020 in patients with extensively pretreated refractory colorectal cancer metastatic to the liver. Hum Gene Ther, 21, 1119-28.

[47] Stoeckel, J., \& Hay, J. G. (2006). Drug evaluation: Reolysin--wild-type reovirus as a cancer therapeutic. Curr Opin Mol Ther, 8, 249-60.

[48] Park, B. H., Hwang, T., Liu, T. C., Sze, D. Y., Kim, J. S., Kwon, H. C., Oh, S. Y., Han, S. Y., Yoon, J. H., Hong, S. H., Moon, A., Speth, K., Park, C., Ahn, Y. J., Daneshmand, M., Rhee, B. G., Pinedo, H. M., Bell, J. C., \& Kirn, D. H. (2008). Use of a targeted oncolytic poxvirus, JX-594, in patients with refractory primary or metastatic liver cancer: a phase I trial. Lancet Oncol, 9, 533-42. 
[49] Pedersen, J. V., Karapanagiotou, E. M., Biondo, A., Tunariu, N., Puglisi, M., Denholm, K. A., Sassi, S., Mansfield, D., Yap, T. A., De Bono, J. S., \& Harrington, K. J. (2011). A phase I clinical trial of a genetically modified and imageable oncolytic vaccinia virus GL-ONC1 with clinical green fluorescent protein (GFP) imaging. J Clin Oncol, 29, abstr 2577.

[50] Minchinton, A. I., \& Tannock, I. F. (2006). Drug penetration in solid tumours. Nature Rev Cancer, 6, 583-92.

[51] Pipiya, T., Sauthoff, H., Huang, Y. Q., et al. (2005). Hypoxia reduces adenoviral replication in cancer cells by downregulation of viral protein expression. Gene Ther, 12, 911-17.

[52] Cappellani, A., Zanghi, A., Di Vita, M., Zanet, E., Veroux, P., Cacopardo, B., Cavallero, A., Piccolo, G., Lo, Menzo. E., Merabito, P., et al. (2010). Clinical and biological markers in gastric cancer: update and perspectives. Front Biosci, 2, 403-412.

[53] García-Bilbao, A., Armañanzas, R., Ispizua, Z., Calvo, B., Alonso-Varona, A., Inza, I., Larrañaga, P., López-Vivanco, G., Suárez-Merino, B., \& Betanzos, M. Identification of a biomarker panel for colorectal cancer diagnosis. BMC Cancer, 12, 43.

[54] Ascierto, M. L., Worschech, A., Yu, Z., Adams, S., Reinboth, J., Chen, N. G., Pos, Z., Roychoudhuri, R., Di Pasquale, G., Bedognetti, D., Uccellini, L., Rossano, F., Ascierto, P. A., Stroncek, D. F., Restifo, N. P., Wang, E., Szalay, AA, \& Marincola, F. M. (2011). Permissivity of the NCI-60 cancer cell lines to oncolytic Vaccinia Virus GLV-1h68. BMC Cancer, 11, 451.

[55] Barretina, , et al. (2012). The Cancer Cell Line Encyclopedia enables predictive modelling of anticancer drug sensitivity. Nature, 483, 603-7.

[56] Dangles-Marie, V., Pocard, M., Richon, S., Weiswald, L. B., Assayag, F., Saulnier, P., Judde, J. G., Janneau, J. L., Auger, N., Validire, P., Dutrillaux, B., Praz, F., Bellet, D., \& Poupon, M. F. (2007). Establishment of human colon cancer cell lines from fresh tumors versus xenografts: comparison of success rate and cell line features. Cancer Res, $67,398-407$.

[57] Rehfeldt, F., Engler, A. J., Eckhardt, A., Ahmed, F., \& Discher, D. E. (2007). Cell responses to the mechanochemical microenvironment--implications for regenerative medicine and drug delivery. Adv Drug Deliv Rev, 59, 1329-1339.

[58] Kanwar, S. S., Yu, Y., Nautiyal, J., Patel, B. B., \& Majumdar, A. P. (2010). The Wnt/ beta-catenin pathway regulates growth and maintenance of colonospheres. Mol Cancer, 9, 212.

[59] Kunz-Schughart, L. A., Freyer, J. P., Hofstaedter, F., \& Ebner, R. The use of 3-D cultures for high-throughput screening: the multicellular spheroid model. J Biomol Screen, 9(4), 273-85.

[60] Gaedtke, L., Thoenes, L., Culmsee, C., Mayer, B., \& Wagner, E. (2007). Proteomic Analysis Reveals Differences in Protein Expression in Spheroid versus Monolayer 
Cultures of Low-Passage Colon Carcinoma Cells. Journal of Proteome Research, 6, 4111-4118.

[61] Herrmann, R., Fayad, W., Schwarz, S., Berndtsson, M., \& Linder, S. J Screening for Compounds That Induce Apoptosis of Cancer Cells Grown as Multicellular Spheroids. Biomol Screen, 13(1), 1-8.

[62] Tung, , et al. (2011). High-throughput 3D spheroid culture and drug testing using 384 hanging drop array. Analyst, 136, 473-478.

[63] Drewitz, M., Helbling, M., Fried, N., Bieri, M., Moritz, W., Lichtenberg, J., \& Kelm, J. M. (2011). Towards automated production and drug sensitivity testing using scaffold-free spherical tumor microtissues. Biotechnol. J, 6, 1488-1496.

[64] Karlssona, H., Fryknäsa, M., Larssona, R., \& Nygren, P. (2012). Loss of cancer drug activity in colon cancer HCT-116 cells during spheroid formation in a new 3-D spheroid cell culture system. Exp Cell Res, 318(13), 1577-85.

[65] Fan, X., Ouyang, N., Teng, H., \& Yao, H. (2011). Isolation and characterization of spheroid cells from the HT29 colon cancer cell line. Int J Colorectal Dis, 26, 1279-1285.

[66] Rosenberg, D. W., Giardina, C., \& Tanaka, T. (2009). Mouse models for the study of colon carcinogenesis. Carcinogenesis, Feb, 30(2), 183-96.

[67] Moser, A. R., Pitot, H. C., \& Dove, W. F. (1990). A dominant mutation that predisposes to multiple intestinal neoplasia in the mouse. Science, 247, 322-324.

[68] Mc Cart, A. E., Vickaryous, N. K., \& Silver, A. (2008). Apc mice: models, modifiers and mutants. Pathol Res Pract, 204(7), 479-90.

[69] Zbinden, M., Duquet, A., Lorente-Trigos, A., Ngwabyt, S. N., Borges, I., Ruiz, i., \& Altaba, A. (2010). NANOG regulates glioma stem cells and is essential in vivo acting in a cross-functional network with GLI1 and P53. EMBO J, 29, 2659-74.

[70] Rong, S., Bodescot, M., Blair, D., Dunn, J., Nakamura, T., Mizuno, K., Park, M., Chan, A., Aaronson, S., \& Vande, Woude. G. F. (1992). Tumorigenicity of the met proto-oncogene and the gene for hepatocyte growth factor. Mol Cell Biol, 12, 5152-8.

[71] Mendel, D. B., Laird, A. D., Xin, X., Louie, S. G., Christensen, J. G., Li, G., Schreck, R. E., Abrams, T. J., Ngai, T. J., Lee, L. B., Murray, L. J., Carver, J., Chan, E., Moss, K. G., Haznedar, J. O., Sukbuntherng, J., Blake, R. A., Sun, L., Tang, C., Miller, T., Shirazian, S., Mc Mahon, G., \& Cherrington, J. M. (2003). In vivo antitumor activity of SU11248, a novel tyrosine kinase inhibitor targeting vascular endothelial growth factor and platelet-derived growth factor receptors: determination of a pharmacokinetic/pharmacodynamic relationship. Clin Cancer Res, 9, 327-37.

[72] Marzola, P., Degrassi, A., Calderan, L., Farace, P., Nicolato, E., Crescimanno, C., Sandri, M., Giusti, A., Pesenti, E., Terron, A., Sbarbati, A., \& Osculati, F. (2005). Early antiangiogenic activity of SU11248 evaluated in vivo by dynamic contrast-enhanced 
magnetic resonance imaging in an experimental model of colon carcinoma. Clin Cancer Res, 11, 5827-32.

[73] Fong, T. A., Shawver, L. K., Sun, L., Tang, C., App, H., Powell, T. J., Kim, Y. H., Schreck, R., Wang, X., Risau, W., Ullrich, A., Hirth, K. P., \& Mc Mahon, G. (1999). SU5416 is a potent and selective inhibitor of the vascular endothelial growth factor receptor (Flk-1/KDR) that inhibits tyrosine kinase catalysis, tumor vascularization, and growth of multiple tumor types. Cancer Res, 59, 99-106.

[74] Fichtner, I., et al. (2004). Anticancer drug response and expression of molecular markers in early-passage xenotransplanted colon carcinomas. Eur. J. Cancer, 40, 298-307.

[75] Julien, S., Merino-Trigo, A., Lacroix, L., Pocard, M., Goere, D., Mariani, P., Landron, S., Bigot, L., Nemati, F., Cuilliere-Dartigues, P., Weiswald, L. B., Lantuas, D., Morgand, L., Pham, E., Gonin, P., Dangles-Marie, V., Job, B., Dessen, P., Bruno, A., Pierre, A., De The, H., Soliman, H., Nunes, M., Lardier, G., Calvet, L., Demers, B., Prevost, G., Vrignaud, P., Roman-Roman, S., Duchamp, O., \& Berthet, C. (2012). Characterization of a large panel of patient-derived tumor xenografts representing the clinical heterogeneity of human colorectal cancer. Clin Cancer Res, In Press.

[76] Guenot, D., et al. (2006). Primary tumour genetic alterations and intra-tumoral heterogeneity are maintained in xenografts of human colon cancers showing chromosome instability. J. Pathol, 208, 643-652.

[77] Krumbach, R., et al. (2011). Primary resistance to cetuximab in a panel of patient-derived tumour xenograft models: activation of MET as one mechanism for drug resistance. Eur. J. Cancer, 47, 1231-1243.

[78] Vaira, V., Fedele, G., Pyne, S., Fasoli, E., Zadra, G., Bailey, D., Snyder, E., Faversani, A., Coggi, G., Flavin, R., Bosari, S., \& Loda, M. (2010). Preclinical model of organotypic culture for pharmacodynamic profiling of human tumors. Proc Natl Acad Sci $U$ $S$ A, 107, 8352-6.

[79] Buchsbaum, D. J., Zhou, T., Grizzle, W. E., Oliver, P. G., Hammond, C. J., Zhang, S., Carpenter, M., \& Lo, Buglio. A. F. (2003). Antitumor efficacy of TRA-8 anti-DR5 monoclonal antibody alone or in combination with chemotherapy and/or radiation therapy in a human breast cancer model. Clin Cancer Res, 9, 3731-41.

[80] Kern, M. A., Haugg, A. M., Eiteneuer, E., Konze, E., Drebber, U., Dienes, H. P., Breuhahn, K., Schirmacher, P., \& Kasper, H. U. (2006). Ex vivo analysis of antineoplastic agents in precision-cut tissue slices of human origin: effects of cyclooxygenase-2 inhibition in hepatocellular carcinoma. Liver Int, 26, 604-12.

[81] Dame, M. K., Bhagavathula, N., Mankey, C., Da, Silva. M., Paruchuri, T., Aslam, M. N., \& Varani, J. (2010). Human colon tissue in organ culture: preservation of normal and neoplastic characteristics. In vitro Cell Dev Biol Anim, 46, 114-22. 
